\title{
PENGARUH PERCEIVED EASE OF USE, PERCEIVED OF USEFULNESS \\ DAN FINANCIAL RISK TERHADAP INTENTION TO USE PADA BOOKING.COM DI KABUPATEN BADUNG
}

\author{
Made Uttari Pitanatri \\ Politeknik Pariwisata Bali \\ Email: uttari.pitanatri@gmail.com \\ NMS Wijaya \\ Fakultas Pariwisata Universitas Udayana \\ Email: mdsofiawij@gmail.com
}

\begin{abstract}
Online reservation has been gives a easiest way for the tourist interm of booking an accomodation. Ease of use, and perceived of usefullness has been considered as a fundamental concern on decision making in using the online system. Booking.com is one of the online system that frequently used by the tourist. The study aimed to eximine the charasteristic of booking.com user, the effect of perceived ease of use, perceived of usefulness and financial risk om intention to use in Badung Regency. To investigate the hypotheses of the research, data was collected from booking.com user in Badung Regency. A survey was conducted with a sample size of 65 tourist and analized by multiple regresion analysis. The study revealed that perceived ease of use, perceived of usefulness and financial risk positively affect intention to use.
\end{abstract}

Keywords: financial risk, intention to us, perceived ease of use and perceived of usefulness

\section{Pendahuluan}

Industri pariwisata telah masuk ke era digital yaitu dengan penggunaan internet sebagai media promosi, penjualan dan transaksi. Perkembangan teknologi informasi juga membuat berwisata menjadi lebih mudah. Di industri pariwisata, para pelaku usaha menggunakan internet untuk mempromosikan usaha dan jasa mereka kepada para konsumennya. Selain digunakan oleh para pelaku usaha pariwisata, internet juga telah digunakan oleh wisatawan (Ekonomi Akurat 2017). 
Sistem reservasi secara online merupakan salah satu kemudahan bagi wisatawan dalam melakukan perjalanan wisata karena dapat menghemat waktu. Berdasarkan wawancara awal dengan para pengguna sistem reservasi online, para pengguna sistem reservasi online cenderung menggunakan aplikasi Booking.com, Agoda, Traveloka, dan Airbnb. Diantara berbagai sistem reservasi online yang ada, booking.com merupakan salah satu situs reservasi secara online yang menarik untuk diteliti. Booking.com merupakan Online Travel Agent (OTA) yang bergerak pada bidang akomodasi dan perjalanan wisata dan merupakan situs perjalanan wisata terbesar di dunia. Booking.com memimpin posisi pada online booking di dunia untuk reservasi pada akomodasi (Booking Holding, 2017).

Booking.com merupakan OTA dengan tingkat penggunaan paling mudah (ease of use) dibandingkan dengan situs pemesanan kamar lainnya seperti Agoda dan Airbnb, yaitu dengan tingkat kemudahan sebesar 81\% (Choice 2019). Selain mudah digunakan, Booking.com juga memberikan beberapa fitur layanan yang bermanfaat (usefull) bagi penggunanya, seperti pemesanan penerbangan, penyewaan mobil, tour, dan taxi airport. Dari segi finansial booking.com memiliki filter free cancelation di hampir semua kamar dan harga kamar yang jelas tanpa biaya tambahan lainnya.

Kabupaten Badung merupakan Kabupaten yang memiliki tingkat hunian kamar tertinggi di Bali, yaitu sebesar 70,32\% dan merupakan salah satu Kabupaten yang memiliki fasilitas hotel berbintang (Merdeka, 2018). Kuta, Jimbaran, Nusa Dua, Tanjung Benoa dan Uluwatu merupakan daerah tujuan wisata utama yang dimiliki oleh Kabupaten Badung.

Saat ini, wisatawan dapat melakukan self service untuk perjalanannya sendiri. Cara perjalanan wisatawan saaat ini telah berubah dengan adanya internet. Perubahan ini mulai dari cara wisatawan dalam mencari informasi, memesan kamar hotel yang diinginkan hingga pembayaran yang dilakukan secara online. Promosi secara digital saat ini sangat relevan untuk digunakan karena adanya perubahan gaya 
hidup wisatawan yang cepat dan bersentuhan langsung dengan internet. Sejalan dengan hal tersebut, promsi digital juga digunakan untuk meningkatkan citra yang baik di mata konsumen (Nasional Sindonews, 2018).

Dalam menentukan pilihan terhadap hotel, wisatawan akan memilih dan membandingkan produk yang ada sebelum menetapkan keputusan pembelian. Perilaku tamu yang beragam ini menyebabkan hotel melakukan pendekatan kepada konsumennya untuk dapat mengetahui preverensi tamu mereka. Terlihat dengan jelas bahwa perkembangan teknologi internet telah mendorong terjadinya perubahan perilaku tamu dalam membuat reservasi kamar.

\section{Tinjauan Pustaka}

\section{Perceived Ease of Use}

Perceived ease of use atau persepsi kemudahan penggunaan, diartikan sebagai tingkat kepercayaan seseorang ketika ia menggunakan suatu sistem, dalam artian bahwa dalam penggunaan sistem tersebut ia tidak mengeluarkan usaha apapun atau free of effort (Davis,1989). Sejalan dengan hal tersebut, Chuttur (2009) an Surendran (2012) menyatakan bahwa pengguna tidak mengharapkan adanya kesulitan ataupun kesusahan ketika mereka mempelajari dan menggunakan sistem teknologi tersebut. Dalam konteks online buying, perceived ease of use merupakan persepsi seseorang bahwa berbelanja melalui internet tidak menggunakan usaha yang besar, atau dapat dikatakan mudah (Md Johar dan Awallud, 2011). Menurut Vankatesh dan Balla (2008) yang senada dengan Alomary dan Wollard (2015), mengukur perceived ease of use didasarkan kepada 6 faktor, (computer self efficacy, perception of external control, computer anxiety, computer playfullnes, perceived enjoyment, dan objective useability). 


\section{Perceived of Usefulnes}

Perceived of usefullness didefinisikan sebagai tingkatan kepercayaan seseorang bahwa menggunakan suatu teknologi ataupun sistem tertentu, akan dapat meningkatkan kinerja serta performa mereka (Davis, 1989). Fadare et al (2016) menambahkan bahwa seseorang akan menggunakan sistem teknologi tertentu jika mereka memiliki tingkat kepercayaan bahwa sistem teknologi tersebut dapat membantu mereka untuk menyelesaikan pekerjaan lebih baik. Keberadaan perceived of usefulness langsung memengaruhi niat perilaku untuk menggunakan. Perceived of usefulness memiliki dampak langsung pada niat perilaku untuk menggunakan teknologi (behavioral intention to use), (Fadare et al, 2016). Perceived of usefullnes dapat menjadi alasan utama bagi konsumen untuk melakukan keputusan pembelian dalam konteks hotel booking (Agag dan El-Masry, 2016).

\section{Financial Risk}

Finansial risk merupakan rasa ketidakpastian seseorang ataupun konsumen pada saat mereka akan membuat pembayaran (Grable, 2000). Senada dengan hal itu, Bart et al (2000) menyampaikan bahwa ketika harga suatu barang ataupun jasa rendah, maka konsumen akan memcari informasi yang lebih dalam mengenai produk ataupun jasa yang mereka inginkan. Hal ini dilakukan untuk mengurasi faktor resiko finansial yang akan dihadapi oleh konsumen. Dalam konteks pembelian secara online, Maignan dan Lucas (1997) menyatakan bahwa finansial risk merupakan persepsi mengenai nilai uang yang bisa lenyap ketika konsumen berbelanja secara online.

\section{Intention To Use}

Sebelum konsumen melakukan keputusan pembelian kamar hotel secara online, ada beberapa tahapan yang dilakukan oleh konsumen (Wolfe et all, 2004). Tahap pertama adalah tahap pencarian informasi (Grau, 2005; Oorni, 2004). Teo (2002) menyatakan bahwa dalam memutuskan pembelian secara online, 50 persen dari 
respondennya menghabiskan waktu yang cukup banyak. Konsumen melakukan proses pencarian secara online dengan alasan yang bervariasi (Teo, 2002), namun alasan yang paling utama dalam pencarian informasi ini adalah untuk memastikan bahwa konsumen mendapatkan penawaran terbaik (best deal), pilihan terbaik (best choice) dan serta cocok bagi mereka (most suitable). Tahap kedua adalah tahap penyeleksian hotel. Konsumen pada umumnya melihat nilai yang mereka dapat berdasarkan harga dari kamar hotel untuk biaya yang mereka keluarkan. Tahap ketiga adalah hotel booking. Dalam melakukan hotel online booking, tiap konsumen memiliki preferensi yang berbeda-beda.

\section{Metodelogi Penelitian}

Penelitian ini menggunakan penelitian kuantitatif yang didukung dengan pendekatan kualitati yang diperoleh dari penelitian serta data-data yang didapatkan dari wawancara dari pihak Sales Manager dan juga wisatawan yang melakukan online booking melalui booking.com di Kabupaten Badung.

Data dikumpulkan dengan cara menyebarkan kuesioner kepada para wisatawan di Kabupaten Badung. Wisatawan yang dipilih adalah wisatawan yang pernah menggunakan Booking.com untuk memesan kamar dan juga wawancara dengan Departemen Sales Marketing Hotel di Kabupaten Badung. Data kuantitatif di dapatkan di lapangan yang dikumpulkan melalui kuesioner mengenai niat wisatawan untuk memesan kamar secara online melalui Booking.com di Kabupaten Badung.

Populasi dalam penelitian ini adalah seluruh wisatawan yang telah memesan kamar hotel melalui booking.com dengan teknik pengambilan sampel secara purposive. Sampel merupakan wisatawan yang sudah pernah melakukan pemesanan kamar di hotel melalui online reservation di situs booking.com. Besarnya jumlah sampel tergantung dengan jumlah indikator dan dikalikan 5. Indikator yang 
digunakan berjumlah 13 indikator, sehingga jumlah sampel minimal yang akan diperlukan adalah berjumlah $13 \times 5=65$ buah sampel. Teknik analisis data dilakukan dengan cara: 1) uji validitas dan reliabilitas dengan menggunakan korelasi produst moment dimana nilai cronbach's alpha harus memiliki nilai lebih tinggi dari 0,$7 ; 2$ ) uji asumsi klasik; 3) Menganalisis dengan Regresi linier berganda untuk mengetahui arah hubungan masing-masing variable independek terhadap variable dependen, 4) uji Koefisien Determinasi; 5) Uji F untuk menguji pengaruh variable bebas terhadap variable terikat; dan 5) analisis korelasi berganda; dan 6) Uji F (secara simultan).

\section{Hasil dan Pembahasan}

\section{Analisis Regresi Linier Berganda}

\section{Coefficients $^{\mathrm{a}}$}

\begin{tabular}{|c|c|c|c|c|c|}
\hline \multirow[b]{2}{*}{ Model } & \multicolumn{2}{|c|}{$\begin{array}{c}\text { Unstandardized } \\
\text { Coefficients }\end{array}$} & \multirow{2}{*}{$\begin{array}{l}\text { Standardized } \\
\text { Coefficients } \\
\text { Beta }\end{array}$} & \multirow[t]{2}{*}{$\mathrm{t}$} & \multirow[t]{2}{*}{ Sig. } \\
\hline & B & Std. Error & & & \\
\hline (Constant) & $\underline{.310}$ & .247 & & 1.256 & .214 \\
\hline Perceived Ease of Use (X1) &.$\underline{350}$ & .145 & .330 & 2.405 & .019 \\
\hline Perceived Usefullness (X2) & .248 & .102 & .234 & 2.433 & .018 \\
\hline Financial Risk (X3) & .349 & .118 & .393 & 2.964 & .004 \\
\hline
\end{tabular}

a. Dependent Variable: Intention to Use $(Y)$

Berdasarkan tabel tersebut diperoleh model regresi berganda yang terbentuk pada penelitian ini adalah sebagai berikut:

Persamaan regresi linear berganda sebagai berikut:

$Y=a+b 1 X 1+b 2 X 2+\ldots . .+b n X n$

$\mathrm{Y}=0.310+0.350 \mathrm{X} 1+0.248 \times 2+0.349 \times 3$ 
Pengujian Hipotesis Penelitian

Adapun Hipotesis pada penelitian ini adalah:

a. Perceived ease of use (X1) berpengaruh signifikan terhadap intention to use (Y).

b. Perceived of usefullness (X2) berpengaruh signifikan terhadap intention to use (Y).

c. Financial risk (X3) berpengaruh signifikan terhadap intention to use (Y).

\section{Uji Koefisien Determinasi (R2)}

\begin{tabular}{|c|c|c|c|c|c|}
\hline \multicolumn{6}{|c|}{ Model Summary ${ }^{b}$} \\
\hline Model & $\mathrm{R}$ & R Square & $\begin{array}{l}\text { Adjusted R } \\
\text { Square }\end{array}$ & $\begin{array}{l}\text { Std. Error of the } \\
\text { Estimate }\end{array}$ & Durbin-Watson \\
\hline 1 & $.912^{a}$ & .831 & .823 & .29986 & 1.446 \\
\hline
\end{tabular}

a. Predictors: (Constant), Financial Risk (X3), Perceived Usefullness (X2), Perceived Ease of Use $(\mathrm{X} 1)$

b. Dependent Variable: Intention to Use $(\mathrm{Y})$

\section{Analisis Korelasi Berganda}

Model Summary ${ }^{\mathrm{b}}$

\begin{tabular}{rl|r|r|r|r}
\hline Model & R & R Square & \multicolumn{2}{|c|}{$\begin{array}{c}\text { Adjusted R } \\
\text { Square }\end{array}$} & \multicolumn{2}{c}{$\begin{array}{c}\text { Std. Error of the } \\
\text { Estimate }\end{array}$} & Durbin-Watson \\
\hline 1 & $\underline{.912^{\mathrm{a}}}$ & .831 & .823 & .29986 & 1.446 \\
\hline
\end{tabular}

a. Predictors: (Constant), Financial Risk (X3), Perceived Usefullness (X2), Perceived Ease of Use $(\mathrm{X} 1)$

b. Dependent Variable: Intention to Use (Y) 


\section{Uji F (Uji Simultan)}

\begin{tabular}{|c|c|c|c|c|c|c|}
\hline & \multicolumn{6}{|c|}{ ANOVA $^{a}$} \\
\hline & Model & Sum of Squares & $\mathrm{df}$ & Mean Square & $\mathrm{F}$ & Sig. \\
\hline \multirow[t]{3}{*}{1} & Regression & 26.949 & 3 & 8.983 & $\underline{99.903}$ & $.000^{\mathrm{b}}$ \\
\hline & Residual & 5.485 & 61 & .090 & & \\
\hline & Total & 32.434 & 64 & & & \\
\hline
\end{tabular}

a. Dependent Variable: Intention to Use (Y)

b. Predictors: (Constant), Financial Risk (X3), Perceived Usefullness (X2), Perceived Ease of Use $(\mathrm{X} 1)$

Penelitian ini telah lolos uji validitas dan uji reliabilitas serta uji asumsi klasik. Pada analisis regresi linear berganda diperoleh hasil perceived ease of use (X1) berpengaruh positif terhadap intention to use (Y) semakin tinggi perceived ease of use maka semakin tinggi intention to use, perceived usefullness (X2) berpengaruh positif terhadap intention to use (Y) semakin tinggi perceived usefullness maka semakin tinggi intention to use dan financial risk (X3) berpengaruh positif terhadap intention to use (Y) semakin tinggi financial risk maka semakin tinggi intention to use. Sedangkan untuk koefisien determinasi diperoleh hasil variabel intention to use (Y) dijelaskan Sebesar $82.3 \%$ oleh variabel perceived ease of use (X1), perceived usefullness (X2), dan financial risk (X3) sisanya tidak dijelaskan di dalam model ataupun model penelitian, dan dijelaskan oleh variabel lain.

Analisis uji $\mathrm{F}$ berdasarkan tabel ANOVA diperoleh nilai $\mathrm{F}$ hitung sebesar 99.903. Nilai F hitung ini lebih besar dari nilai F table sebesar 2.76 dan nilai signifikansi F sebesar 0.000 nilai ini lebih kecil dari 0.05, sehingga dapat disimpulkan bahwa terdapat pengaruh signifikan perceived ease of use (X1), perceived usefullness (X2), financial risk (X3) terhadap variabel terikat yaitu intention to use (Y) secara simultan. 
Hasil pengujian hipotesis diperoleh hasil penelitian menunjukkan perceived ease of use memiliki positif serta signifikan terhadap intention to use. Pengguna menganggap bahwa Booking.com merupakan sistem reservasi online yang mudah untuk digunakan dan mempengaruhi niat untuk menggunakan booking.com. Sejalan dengan perceived ease of use, perceived usefullness juga memiliki pengaruh positif serta signifikan terhadap intention to use dari Booking.com. Semakin banyak fitur yang memberikan manfaat, maka semakin besar keinginan pengguna untuk menggunakan booking.com. Financial risk berpengaruh positif dan signifikan terhadap intention to use. Resiko finansial mempengaruhi minat wisatawan untuk menggunakan booking.com, semakin kecil resiko finansial yang akan dihadapi konsumen, maka semakin besar keinginan konsumen untuk menggunakan Booking.com, dan juga semakin tinggi tingkat keamaan dari Booking.com maka semakin besar keinginan wisatawan untuk memakai booking.com untuk memesan kamar secara online.

\section{Kesimpulan dan Saran}

\section{Kesimpulan}

Pertama, Perceived Ease of Use memiliki pengaruh positif serta signifikan terhadap intention to use. Pengguna menganggap bahwa Booking.com merupakan sistem reservasi online yang mudah untuk digunakan dengan adanya filtrasi dan informasi yang jelas. Kemudahan ini mempengaruhi niat untuk menggunakan booking.com. Kedua, Perceived usefullness memiliki pengaruh positif serta signifikan terhadap intention to use. Booking.com memberikan banyak manfaat bagi penggunanya. Keinginan pengguna untuk menggunakan Booking.com akan semakin besar jika Booking.com dapat memberikan semakin banyak fitur yang bermanfaat. Ketiga, Financial risk berpengaruh positif dan signifikan terhadap intention to use. Resiko finansial mempengaruhi minat wisatawan untuk menggunakan booking.com 
Pengguna booking.com percaya bahwa bertransaksi di booking.com merupakan hal yang aman dan menguntungkan bagi mereka dari segi finansial.

\section{Saran}

Pertama, mempertahankan kemudahan penggunaan yang ada pada booking.com dengan menambah filtrasi-filtrasi yang dapat membantu pemesanan akomodasi ataupun perjalanan wisata sehingga tetep penggunaannya tetep diminati. Filtrasi-filtrasi ini dapat seperti filtrasi akomodasi untuk keluarga, millenial ataupun orang tua. Penambahan tujuan menginap juga sebaiknya ditambahkan dalam filtrasi, seperti tujuan untuk honeymooner, business dan travelling, ataupun tujuan lainnya. Kedua, Mempertahankan fitur-fitur yang sudah ada dengan lebih meningkatkan fitur-fitur yang jarang terpakai seperti airport taxis, car rental dan attractions. Disarankan juga untuk dapat menambah rekomendasi untuk restaurant hingga objek wisata yang saat ini belum ada pada booking.com. Ketiga, Menambah filter perbandingan harga dengan online travel agent lainnya atau dengan website hotel resmi, dengan mencantumkan kelebihan dari booking.com seperti free cancelation, pay later dan no prepayment, sehingga pengguna lebih mudah tertarik untuk menggunakan booking.com.

\section{Daftar Pustaka}

Agag, G., \& El- Masry, A.A (2016). Understanding customer intention to participate in online travel community and effects on customer intention to purchase travel online and WOM: An integration of innovation diffusion theory and TAM with trust. Computers Humans Behavior,60, 97-111.

Alomary, Azzadan John Wollard. 2015. How Is Technology Accepted bUsers? a Review of Technology Acceptance Models and Theories. International Journal University of Southampton. University of Southampton. London.

Bart, Yakov et al. (2005). Are The Drivers and Role of Online Trust the Same for All Web Sites and Consumers? A Large-Scale Exploratory Empirical Study. Journal of Marketing, Vol. 69, 133-152. 
Booking holding. 2017. Booking Holding, sumber http://ir.bookingholdings.com/node/23191/html Diakses 9/1/2019.

Choice. 2019. Hotelking Site Compare: Booking.com, Expedia, Wotif, Hotels.com adn More,Sumber:https://www.choice.com.au/travel/accommodation/hotels/buyi ng-guides/hotel-bookingDiakses 9/1/2019.

Chuttur, Mohammad. (2009). Overview of the Technology Acceptance Model: Origins, Developments and Future Directions. Ais Electronic Library. ISSN 15356078.

Davis, F. D. (1989). Perceived Usefulness, Perceived Ease of Use, and User Acceptance of Information Technology. MIS Quarterly Vol. 13, No. 3: 319-340.

Ekonomi Akurat. 2017. "Pesatnya Pengguna Internet, Peluang Bagi Industri Perhotelan", Sumber: https://ekonomi.akurat.co/id-89231-read-pesatnyapenguna-internet-peluang-bagi-industri-perhotelan Diakses 13/12/2017.

Fadare, O. A, Ibrahim, M. B., \& Edogbanya, A. (2016). A Survey on Perceived Risk and Intention of Adopting Internet Banking. Journal of Internet Banking and Commerce, 21(1), 1-21.

Grable, John. (2002) . Financial Risk Tolerance and Additional Factors That Affect Risk Taking in Everyday Money Matters. Journal of Business and Psychology 14(4), 625-630 ; DOI: 10.1023/A:1022994314982.

Grau, J. (2005, November 11). How consumers use online for travel. iMedia Connection. $\quad$ Retrieved June, 2007, from http://www.imediaconnection.com/content/7255.asp.

Maignan, I., \& Lukas, B. A. (1997). The Nature and Social Uses of the Internet : A Qualitative Investigation. Journal of Consumer Affairs, 346-371.

MdJohar, M., \&Awallud, J. A. (2011). The Role of Technology Acceptance Model in Explaining Effect on E-Commerce Application System. International Journal of Managing Information Technology (IJMIT), No 33.

Merdeka. 2018. Pasca Erupsi Gunung Agung, Jumlah Kunjungan Turis di Bali Meningkat, sumber: https://www.merdeka.com/uang/pasca-erupsi-gunungagung-jumlah-kunjungan-turis-di-bali-meningkat.html.

Nasional Sindonews. 2018. Tren Pariwisata 2018. Sumber: https://nasional.sindonews.com/berita/1266733/18/tren-pariwisata-2018.

Oorni, A. (2004). Consumer objectives and the amount of search in electronic travel and tourism markets. Journal of Travel \& Tourism Marketing, 17(2/3), 3-14.

Surendran, Priyanka. (2012) . Technology Acceptance Model: A Survey of Literature. International Journal of Business and Social Research (IJBSR), vol. 2(4). 
Teo, T.S.H. (2002). Attitudes toward online shopping and the Internet. BehaviourE Information Technology, 21(4), 259-271.

Venkatesh, V., \&Bala, H. (2008). Technology acceptance model 3 and a research agenda on interventions. Decision sciences, 39(2), 273-315.

Venkatesh, V., \&F. D. Davis. (1996). A Model of the Perceived Ease of Use Development and Test.Decision Sciences, 27/3: 451-481.

Vankatesh, Viswanath et.al. (2016). User Acceptance of Information Technology: Toward a Unified View. MIS Quarterly Vol. 27, No. 3, 425-478.

Wolfe, et al. (2004).Image assessment for a destination with limited comparative advantages.Tourism management25, 121-126.

\section{Profil Penulis}

Made Uttari Pitanatri, pengajar di Politeknik Pariwisata Bali dan telah berkecimpung selama 5 tahun di dunia kerjasama industry serta dunia pendidikan di bidang Front Office, terutama pada bidang reservation. Tertarik dengan tema-tema pendidikan hospitality yang berhubungan dengan social media dan pemasaran digital. Saat ini mulai aktif sebagai peneliti pemula dan telah menulis di buku Kamala serta sebagai penulis dalam kegiatan FGD dengan tema Strategi Pemasaran Digital pada Masa Pandemi Covid-19.

Ni Made Sofia Wijaya, dosen di Fakultas Pariwisata Universitas Udayana yang telah menyelesaikan program doctor di Yamaguchi University Japan dan hingga saat ini aktif menulis. Tertarik dengan tema-tema community based tourism dan rural tourism. 